\title{
Degrees of success: Meeting professional standards through distance e-learning
}

Richard THAIN, United Kingdom, Director, Hydrographic Academy, Plymouth University Anthony JENKS, United Kingdom, Lecturer e-learning for Hydrography, Plymouth University Andrew McNEILL, United Kingdom, Global Learning and Development Manager, Fugro Don VENTURA, USA, Hydrographic Survey Manager, Fugro-Pelagos Inc Topic L: The hydrographic profession

\section{INTRODUCTION}

Higher education programmes for those wishing to enter the hydrographic surveying profession are generally available on an attendance basis at a limited selection of academic institutions. The number of places available on such courses is not sufficient to satisfy demand from the offshore industry, with the result that there has been a particular shortage of appropriately qualified personnel in the hydrographic survey, positioning and inspection fields. Shell's Chief Surveyor recognised this fact in an article in the trade press in April 2008, in which he expressed the industry's concern over the "current shortage and future supply of qualified, experienced and competent surveyors, which does represent a 'pinch-point' for the UK oil and gas industry" (Whitcombe, 2008).

By the nature of the work involved, the offshore hydrographic survey industry workforce is deployed frequently for extended periods in remote locations, often at sea aboard ships. Despite advances in technology, communications bandwidth is very expensive and thus usually limited to operational transmissions. There is very little opportunity for individuals to access the internet through a broadband connection on a regular basis, and sporadic plain text emails, and occasional satellite phone calls are all that are normally available. In this high-value, short-staffed industry, it is not normally viable for companies to release their personnel for, say, 12 months for full-time study to gain a postgraduate qualification and appropriate professional body recognition. Workforce development for the offshore hydrographic survey industry is, therefore, a challenge, and even the largest survey and geomatics companies have very few opportunities to engage with the higher education sector.

Plymouth University (School of Marine Science and Engineering), Fugro and the Royal Navy's Hydrographic School at FOST HM ${ }^{1}$ formed a working partnership to address the issues outlined above, with Fugro acting as 'industry advisers' and the Royal Navy agreeing to provide advice and assistance as required; especially useful as they already run recognised and accredited courses for

\footnotetext{
${ }^{1}$ Flag Officer Sea Training, Hydrography and Meteorology
} 
working professionals. Funding was provided initially through the UK government, in the form of a grant from the South West Spoke of the National HE STEM ${ }^{2}$ programme, and The Hydrographic Academy (HA) project commenced formally from January 2011.

\section{METHODS}

Distance e-learning is well established as an effective method of delivery of teaching and learning materials in higher education. Examples are numerous, and include the offerings from the UK Open University, and the Royal Veterinary College's MSc programme. This report does not aim to give a comprehensive review of the literature relating to the design and provision of distance and e-learning, however, some of the key teaching and learning considerations relating to the design of the Hydrographic Academy's e-learning environment and course materials are as follows (adapted from Porter, 2004):

- To facilitate an individual's learning

- To bring together students from diverse locations, with individual interests, skills and needs to form learning communities

- To state expectations clearly

- To set and maintain rigorous academic standards, and communicate expectations clearly

- To be adaptable with regard to a learner's needs

- To communicate clearly and effectively

- To make consideration of the different abilities and learning styles of students

- To encourage discussion, debate and critical thinking

Early research also indicated that all learning materials would have to meet the learning styles and preferences of different types of students, be able to be used by students across platforms and differing levels of technology, be portable; and also all learners would have to be supported by a tutor, available regularly to individual students for advice and to deal with subject specific and general academic queries. It was decided to use balanced approach of constructivism and behaviourism, whereby students are 'lectured' in some way and are then exposed to practical applications and activities. With these considerations in mind, a 10 credit introductory module was developed, representing an entry point for both potential undergraduates and postgraduates. This module was accredited through Plymouth University's Continuous Professional Development (CPD) framework as a stand-alone unit.

\footnotetext{
${ }^{2}$ Higher Education, Science Technology Engineering Mathematics
} 
With the medium of e-learning in mind, a coherent suite of learning materials was developed for the first HA module. This collection of materials has been dubbed the Total Learning Package (TLP), and was designed carefully by the learning technology team at Plymouth University to provide an easily navigable route through the module. Presenting a familiar HTML-type, web browser environment makes it second nature for anyone familiar with the internet to navigate. Seamless integration with online materials can be achieved as and when an internet connection is available. Critically, the entire TLP was packaged onto discrete media (in this case, an 8GB USB memory stick), and physically send to the student. The complete materials for the first module could be contained within one stick, and it thus represents a convenient method for students working offshore to take their learning environment with them.

The student experience when engaging with the TLP is typically as follows:

- Listen to a series of short, narrated PowerPoint lectures of typically less than 20 minutes each

- Complete a selection of challenging self-test formative questions

- Conduct some directed background reading, which may be supplied as part of the TLP or may have to be downloaded when internet connection allows

- Research and write a short essay or report on a subject related to a lecture or series of lectures

- Compile the essays and reports into a coherent portfolio which is directly related to professional practice, and is submitted for marking at the end of the module

In total, the TLP for Module 1 (10 academic credits at Level 4) represents 100 student study hours. A group of twelve students, all Fugro employees and sponsored by Fugro was enrolled electronically at the University in January 2012 to study the first module offered by the Hydrographic Academy. This 10 credit level 4 (first year undergraduate) module was run over a 10 week period, with evaluation being conducted throughout.

\section{RESULTS}

Significantly, the development time for the Hydrographic Academy's first module was found to be typical of the investment required to create a high-quality, accredited distance learning programme. It is estimated that approximately 4,500 man hours were expended in creating the teaching and learning materials for this module alone. 
As expected, the majority of the students did not have a broadband internet connection for much of the time they were enrolled on the module (Figure 2), but importantly, $100 \%$ of the students replied affirmatively that the "format and style in which the module was presented was an effective way to learn". The tutor support provided to the students was also seen as a critical element of success. Support was not provided on a $24 \mathrm{hr}$ basis or at weekends, and limited to the normal working day, although a response within two working days or sooner was guaranteed. The student group found this element extremely useful, with the majority of individuals contacting their tutor on a weekly basis. Additional qualitative feedback was sought through the Creative Learning Journey (CLJ) model. It has been used as a means to facilitate and capture the collaboration and learning processes between partners engaged in a project, and has been employed successfully by the Manchester Beacon at the University of Manchester ${ }^{3}$. The overall CLJ for the first module can be viewed on the Creative STEM website 4 . A shortened version of this film can be found on the HA website, www.plymouth.ac.uk/hydro.

\section{DISCUSSION}

The trial of the Hydrographic Academy's first module has been a remarkable success. There has been positive quantitative and qualitative feedback from Fugro, the group of trial students, the professional bodies, from Plymouth University management and from those prospective students who continue to register their interest. Quotes received from students completing the first module appear below:

- "I have quite literally searched the world for an institution that offers this kind of tertiary education and from Australia to Europe I have been unsuccessful so thank you for your efforts! It's a huge step in the right direction!"

- "The course syllabus looks great! Establishing the Hydrographic Academy is a great initiative!"

- "It's great to have all the materials to be able to access the lectures and notes as and when I have time. It's very comprehensive, there are a lot of materials and it's a great opportunity for me to be able to study like this."

- "The content is easy to navigate through and it is very impressive. I was thinking there may be some key areas where I would need some extra information but that wasn't the case. I am very impressed with the course content and materials"

\footnotetext{
${ }^{3}$ www.manchesterbeacon.org

${ }^{4}$ http://www.creativestem.co.uk/
} 
- $\quad$ "The Hydrographic Academy has given me the chance to fill a gap in my CV and develop my theoretical knowledge whilst helping me to progress my career within the industry"

Significant developmental work remains in designing and producing elements of the Hydrographic Academy's future modules, in particular, the practical study elements. Practical hydrographic surveying will be predominantly taught through two residential sessions, although significant efforts are being expended to incorporate practical elements (data processing and survey planning, for example) within the e-learning materials.

\section{CONCLUSION}

E-learning is a well-proven method of providing higher education opportunities for busy working professionals, although it had not been applied in a comprehensive sense within the hydrographic survey industry before the developments introduced by the Hydrographic Academy at Plymouth University. There are numerous challenges posed by the unique nature of the offshore survey business, including limited internet access for the majority of prospective students. This aspect, together with the variable and on-call nature of the industry has meant that there have been very limited opportunities for workforce development, for employees to gain Higher Education level qualifications and professional body recognition.

As a partnership between industry and academia, the Hydrographic Academy project has successfully developed and trialled a short academic module for those working at sea or in remote locations. Feedback from learners has been extremely positive, and the quantitative and qualitative feedback received has indicated that learning outcomes can be met through distance e-learning. The project team is continuing to engage widely with the UK higher education sector to ensure that the latest developments in best practice are brought to the Hydrographic Academy, thus ensuring that the needs of the learners, employers and the professional bodies are met.

\section{REFERENCES}

Lynette R. Porter, Developing an online curriculum. Technologies and Techniques. (London: Information Science Publishing, 2004)

David Whitcombe, "Recruit, Train and Retain, " Hydro International April (2008): 26-27 


\section{BIOGRAPHIES}

Richard Thain has been working for Plymouth University since 1999, following a spell of employment in the offshore industry as a hydrographic surveyor. Until 2008, he contributed to the development and delivery of programmes in oceanography, underwater acoustics and meteorology for Plymouth University at Britannia Royal Naval College; and also worked as an Associate Lecturer with the Open University. A founding member and the Education Coordinator for the Centre of Excellence in Naval Oceanographic Research and Education (CENORE), and working closely with the Royal Navy, industry and academia on military-orientated academic research, Richard is now deployed full-time as the Director of the Hydrographic Academy.

Tony Jenks is an e-lecturer in Plymouth University's the Hydrographic Academy, where he brings a wealth of experience gained during 37 years in the Royal Navy. As a specialist hydrographic surveying officer he has conducted surveys all over the world from a variety of ships and boats, as well as fulfilling two key appointments on the staff of the RN hydrographic training school.

Andrew McNeill is Global Learning \& Development Manager for Fugro. Andrew has a BSc in Topographic Science from Glasgow University and an MBA from Robert Gordon University, and has worked in the offshore industry since 1983 progressing through various offshore and onshore technical and management positions, ultimately as Chief Surveyor for Fugro's Offshore Survey Division. He was part of a team that setup the Fugro Academy in 2006 and has managed it in his current position since 2009.

Don Ventura has been involved in hydrography since 1983, when he embarked on a 20-year service with the UK Royal Navy's Hydrographic Squadron. Don's time in the RN saw him gain considerable at-sea and professional experience in a number of ships and disciplines ranging from coastal hydrography for nautical charting, ocean mapping, physical oceanography and deep ocean geophysical surveys. Latterly, Don has supported numerous programmes in his post-Naval career, including operational roles with NOAA's National Data Buoy Center, the joint USACE/NAVOCEANO Joint Airborne Lidar Bathymetry Technical Center of Expertise (JALBTCX) and more recently with Fugro's award-winning bathymetric Lidar services worldwide. Don lives in the United States with wife Jane and his 2 children.

Corresponding author and presenter contact information:

Dr Richard Thain, Director, Hydrographic Academy

Plymouth University, School of Marine Science and Engineering

Drake Circus, Plymouth. PL4 8AA

rthain@plymouth.ac.uk 